\title{
Expression of Toll-like receptor 4 in lungs of immune-suppressed rat with Acinetobacter baumannii infection
}

\author{
YANMEI WANG ${ }^{1 *}$, XIAOHONG ZHANG ${ }^{2 *}$, XUANLIN FENG ${ }^{2}$, XIAOSHU LIU ${ }^{2}$, \\ LEI DENG ${ }^{2}$ and ZONG-AN LIANG ${ }^{3}$ \\ ${ }^{1}$ Department of Intensive Care Unit, Sichuan Second Hospital of Traditional Chinese Medicine, Chengdu, Sichuan 610031; \\ ${ }^{2}$ Department of Emergency Intensive Care Unit, Sichuan Academy of Medical Sciences and Sichuan Province \\ People's Hospital, Chengdu, Sichuan $610072 ;{ }^{3}$ Department of Respiratory and Critical Care Medicine, \\ West China Hospital, Sichuan University, Chengdu, Sichuan 610041, P.R. China
}

Received February 17, 2016; Accepted August 18, 2016

DOI: 10.3892/etm.2016.3624

\begin{abstract}
Toll-like receptor 4 (TLR4) is involved in the regulation of host responses to Acinetobacter baumannii (A. baumannii). The aim of the present study was to examine the function of TLR4 in lung inflammation in immune-suppressed rats with $A$. baumannii infection. A total of 72 Sprague-Dawley male rats were randomly divided into the control, A. baumannii infection and immune-suppressed infection groups. The immune-suppressed infection group was treated with $100 \mathrm{mg} / \mathrm{kg}$ hydrocortisone by subcutaneous injection every other day for 2 weeks prior to A. baumannii infection. Lung tissue was obtained on the 3rd and 7th day after tracheal inoculation with $A$. baumannii. The expression of TLR4 in bronchial and alveolar epithelial cells, and alveolar macrophage was examined using immunohistochemistry. The levels of interleukin (IL)-6, tumor necrosis factor (TNF)- $\alpha$ in bronchoalveolar lavage fluid were detected using ELISA. The results showed that in the control group, the expression of TLR4 was upregulated in the bronchial and alveolar epithelial, and alveolar macrophages, and the levels of IL- 6 and TNF- $\alpha$ were increased in the early phase of $A$. baumannii infection. On the 7th day, no significant difference in the levels of IL-6 and TNF- $\alpha$ was observed between the A. baumannii infection and control groups. Conversely, the expression of TLR4 was downregulated in the immune-suppressed group, and the levels of IL-6 and TNF- $\alpha$ were reduced on the 3rd day after infection. In the subsequent observation period, the expression of TLR4 was upregulated and the levels of IL- 6 and TNF- $\alpha$
\end{abstract}

Correspondence to: Dr Zong-An Liang, Department of Respiratory and Critical Care Medicine, West China Hospital, Sichuan University, 37 Guo Xue Street, Chengdu, Sichuan 610041, P.R. China

E-mail: zong_anliang@163.com

*Contributed equally

Key words: Acinetobacter baumannii, inflammation, Toll-like receptor 4 , immunosuppression were increased. In conclusion, the results show a critical role of TLR4 in mediating effective immune response in the lung of rat with A. baumannii infection.

\section{Introduction}

In recent years, Acinetobacter baumannii (A. baumannii) has become a major nosocomial pathogen and frequent cause of hospital-acquired pneumonia, surgical wound infections and sepsis (1-3). The mortality of A. baumannii-VAP cases in critical care units is $42 \%$ (2), rendering A. baumannii a serious threat to ICU populations.

Toll-like receptors (TLRs), which belong to receptors of type I transmembrane proteins, were widely constitutively expressed in several cell types in lung tissue $(4,5)$. TLRs identified many types of pathogen-associated molecular patterns (PAMPs); transfer PAMP, such as LPS, into the cells through its transmembrane structure; produce complicated signaling cascade, which may induce the activation of nuclear factor $-\kappa \mathrm{B}(\mathrm{NF}-\kappa \mathrm{B})$; induce the synthesis and release of a variety of inflammatory mediators; accelerate the elimination of A. baumannii by primary alveolar macrophages; and start the anti-apoptotic mechanism of lung epithelial cells $(6,7)$. TLR4 expression was downregulated by LPS isolated from multidrugresistant $A$. baumannii by 0.6 -fold (8). Additionally, through the establishment of a mouse model of TLR4 gene knockout it was observed that the bacterial-killing ability against $A$. baumannii was impaired in TLR4-deficient bone marrow-derived macrophages (BMDMs) $(9,10)$. Thus, the physiological significance of TLR4 is to defend micro-organisms, and mediate innate immune responses, in which appropriate inflammation responses were useful in the defense of A. baumannii.

The mechanisms of the induced expression of TLR4 and the intensity of its signal transduction pathway have yet to be clarified. Smoking and high-dose LPS can enhance TLR4 expression of the alveolar macrophages $(11,12)$. In addition, the absence of endotoxin of A. baumannii, the circulatory disturbance of TLR4 receptors on the Golgi apparatus-cell membrane-lysosomal compartment of cells, and the effects of lung microenvironment on the subcellular localization of TLR4 may cause reduced TLR4 expression and the 
elimination of gram-negative bacillus (13-15). Thus, a different expression of TLR4 is associated with the cell type and state of bronchoalveolar and lung cells, the used reagents, and primers (7).

Clinically, patients with low immune function are particularly prone to A. baumannii infection, although the reason for this susceptibility remains to be determined. In ICU patients, because of the high prevalence of $A$. baumannii drug resistance, most $A$. baumannii infections result in severe bacterial infection, respiratory failure or multiple organ failure, with the mortality rate being equivalent to complex cardiovascular and cerebrovascular diseases (2). Thus, the constitutive and induced expression of TLR4 in immunocompromised patients with A. baumannii infection is to be investigated.

In the present study, an immunocompromised rat model with weakened phagocytic function of macrophage was established using hydrocortisone subcutaneous injection for 2 weeks, and the expression and changes of TLR4 in lung of rats with A. baumannii infection were observed. The role of the TLR4-NF- $\mathrm{B}$ pathway in the pathogenesis and development of $A$. baumannii lung infection in immunocompromised hosts was then determined by detecting the expression of interleukin (IL) -6 and tumor necrosis factor (TNF)- $\alpha$ in bronchoalveolar lavage. Control rats efficiently cleared A. baumannii, concurrent with the upregulated expression of TLR4 and a rapid elaboration of IL-6 and TNF- $\alpha$ in bronchoalveolar lavage and a corresponding mobilization of intrapulmonary neutrophils and macrophages. Immunocompromised rats deficient in TLR4 demonstrated a substantial delay in the clearance of A. baumannii with a decreased expression of IL- 6 and TNF- $\alpha$ in bronchoalveolar lavage and a notable absence of intrapulmonary neutrophils and macrophages.

The aim of the present study was to determine the role of TLR4 in contributing to the identification of infection and signaling the innate immune response against A. baumannii.

\section{Materials and methods}

Animal. In total, 72 healthy 6-week-old Sprague-Dawley male rats, weighing 150-180 g, were provided by the Institute of Pharmacology, Sichuan Academy of Traditional Chinese Medicine. The rats were randomly divided into cages at $25 \pm 0.5^{\circ} \mathrm{C}$, and had access to common feed and drinking water ad libitum. The study was approved by theAnimal Ethics Committee of Sichuan Second Hospital of Tradition Chinese Medicine with the approval code of 2014001.

Experimental grouping. Fourteen days prior to the experiment, the rats were randomly divided into the control group (group with normal immune function, physiological saline was used in bronchial drip), infection group (group with normal immune function, A. baumannii suspension was used in bronchial drip), and immune-suppressed infection group (group with restrained immune function, A. baumannii suspension was used in bronchial drip) ( $n=24$ rats per group). For the immune-suppressed infection group, hydrocortisone acetate (100 mg/kg) was subcutaneously injected every other day for 14 days prior to infection. Alveolar macrophage was collected after alveolar lavage to demonstrate weakened phagocytic function of alveolar macrophages. Thus, the rat model with immune-suppressed function was successfully proven. To avoid the development of an adrenal crisis, hydrocortisone acetate $(100 \mathrm{mg} / \mathrm{kg})$ was treated once a day for 7 days after A. baumannii infection.

A. baumannii strains. Bacterial strains were isolated by the Department of Microbiology Laboratory, the Second Hospital of Traditional Chinese Medicine (Sichuan, China), from the sputum of a sepsis patient in the ICU. The strain belonged to pan drug-resistant $A$. baumannii for the conventional drug (all $\beta$-lactams, carbapenems and sulbactam, fluoroquinolones, aminoglycoside, polymyxin, tigecycline and colistin). Prior to the experiment, bacteria strains were cryopreserved in the refrigerator at $-70^{\circ} \mathrm{C}$. On the experiment day, A. baumannii were recovered with the conventional method, the bacterial suspension was inoculated with $2 \mu \mathrm{l}$ and annulus on $35^{\circ} \mathrm{C}$ hydrolysis of casein agar plate $(\mathrm{MH})$ was removed, placed in a constant temperature oscillation incubator (ShanghaiZhicheng Analytical Instrument Manufacturing Corporation, Shanghai, China), incubated for $18 \mathrm{~h}$ at $40 \mathrm{xg}$ and $37^{\circ} \mathrm{C}$, and then standardized to $1 \times 10^{8} \mathrm{CFU} / \mathrm{ml}$ with sterile physiological saline.

A. baumannii infection rat model. The rats were anesthetized using an intraperitoneal injection with $10 \%$ chloral hydrate ( $4 \mathrm{ml} / \mathrm{kg}$ ). The animals were fastened on the operating table in a supine position, and neck skin preparation and disinfection were carried out, prior to exposing the trachea. One hundred microliters $1 \times 10^{8} \mathrm{CFU} / \mathrm{ml}$ suspension of A. baumannii was dropped into the trachea. After tracheal instillation, the animals were maintained erect for $5 \mathrm{~min}$, and then laid down until they became conscious. For the preliminary experiments, the right lower lung of rats was extracted directly for cultivating quantitatively to confirm that the model was successful.

Collecting of lung tissue. The mental state, breathing, eating, drinking water, exercise, temperature, and fur of rats was observed daily and the survival rate was recorded. Two rats were randomly sacrificed with diethyl etheron on the 3rd and 7 th day, and left lung tissue was bronchoalveolar lavaged with Hank's solution, $10 \mathrm{ml}$ each time, 4 times in total. The superior lobe of right lung was collected to produce tissue homogenate, from which $10 \mu \mathrm{l}$ was obtained for A. baumannii quantitative culture. The inferior lobe of the right lung was flushed 5 times with normal saline. Paraffin sections were fixed, dehydrated, and dewaxed in xylene, followed by paraffin-embedding and slicing using $4 \%$ polyformaldehyde. Hematoxylin and eosin (H\&E) staining was subsequently carried out.

$H \& E$ staining. Changes of lung tissue were observed under an optical microscope, and the semi-quantitative analysis of the lung tissue was carried out, using scoring criteria mentioned in Table I. Ten randomly selected high-power fields (x100) were observed on each lung tissue specimen, the score of each field was recorded, and the mean value was obtained.

Immunohistochemistry. Integral optical density (IOD) values of positive cells in lung tissue were detected using Image-Pro Plus 6.0 image analysis system (Armonk, NY, USA). IOD values were used to reflect the expression of positive material in lung tissue. 
Table I. The schedule of pneumonia score.

\begin{tabular}{|c|c|c|c|c|c|}
\hline Pathologic change & 0 scores & 1 scores & 2 scores & 3 scores & 4 scores \\
\hline Capillary blood clot & $\begin{array}{l}\text { No red blood } \\
\text { cells }\end{array}$ & & Only little & More & Almost full of the lumen \\
\hline $\begin{array}{l}\text { The alveolar cavity fibrin } \\
\text { exudation }\end{array}$ & No & & Little & More & Almost full of the lumen \\
\hline Neutrophilic exudate & No & Suspicious & Sporadic & $\begin{array}{l}\text { Small focal } \\
\text { exudation }\end{array}$ & Large area of seepage \\
\hline $\begin{array}{l}\text { Airway mucosa epithelial } \\
\text { cells decreased }\end{array}$ & No & Suspicious & & Partial & Large area \\
\hline $\begin{array}{l}\text { Thickening of alveolar } \\
\text { interval }\end{array}$ & $\begin{array}{l}\text { Relatively } \\
\text { normal }\end{array}$ & $\begin{array}{l}\text { Slightly } \\
\text { broaden }\end{array}$ & & $\begin{array}{l}\text { Significant } \\
\text { broaden }\end{array}$ & Loss of normal structure \\
\hline
\end{tabular}

IL- 6 and TNF- $\alpha$ were detected using enzyme-linked immunosorbent assay (ELISA). Bronchoalveolar lavage fluid (BALF) was collected, and the levels of IL- 6 and TNF- $\alpha$ were detected. The antibody sandwich method was used, and the kit was provided by Shanghai Jiang Lai Biotechnology Co., Ltd. (Shanghai, China).

Statistical analysis. SPSS 13.0 software (Chicago,IL, USA) was used for statistical analysis. Lung bacterialoads were counted logarithmically for each experiment group and compared with the control group. Data were presented as mean \pm standard deviation, and measurement data were expressed using one-way analysis of variance. The LSD method was used when variance was homogeneous, and the non-parametric rank-sum test was used when the variance was not homogeneous. $\mathrm{P}<0.05$ was considered statistically significant.

\section{Results}

$H \& E$ staining. H\&E staining for the control group showed complete capillary bronchiole and alveolar structure, and trace amounts of inflammatory cell infiltration were observed in the early (3rd day) and late phase (7th day). In the A. baumannii infection group, at the earlier time points (3rd day), destructive capillary bronchiole and alveolar structure, widened bronchial and alveolar septum, a large number of inflammatory cells and lymph cell infiltration were observed. On the late 7 th day, a large number of neutrophil infiltrations, unclear alveolar boundary, a fusion between the alveolar, disappeared alveolar structure and a large number of fibroblasts and extracellular matrix were observed. In the immune-suppressed infection group, at the early phase (3rd day), destructive alveolar structure, and pulmonary edema were observed without neutrophil or macrophage infiltration. In the late phase (7th day), neutrophil and macrophage infiltration, and partially restored alveolar structure were evident in capillary bronchus and alveolar. The pathological changes in the lung tissues of each group (H\&E; magnification, x100) are shown in Fig. 1.

Pneumonia score. The scores of the semi-quantitative analysis of the lung tissue at the different time points were determined (Table II). The result showed that compared with the control group, inflammation in the A. baumannii infection group in
Table II. Pathological scores of lung inflammation in each group (mean $\pm \mathrm{SD}$ ).

\begin{tabular}{lcc}
\hline Groups & $\begin{array}{c}\text { Early stage } \\
\text { (3rd day) }\end{array}$ & $\begin{array}{c}\text { Late stage } \\
(7 \text { th day) }\end{array}$ \\
\hline Control & $2.50 \pm 0.29$ & $2.25 \pm 0.31$ \\
Infection & $5.42 \pm 0.23^{\mathrm{a}}$ & $3.083 \pm 0.260$ \\
Immune-suppressed & $11.67 \pm 0.63^{\mathrm{a}, \mathrm{b}}$ & $8.92 \pm 0.514^{\mathrm{a}, \mathrm{b}}$ \\
infection & & \\
\hline
\end{tabular}

Compared with the ${ }^{\mathrm{a}}$ control and ${ }^{\mathrm{b}}$ infection group; both $\mathrm{p}<0.001$.

the early (the 3rd day) period was distinctly aggravated, and the pathological score $(5.42 \pm 0.23)$ was higher $(\mathrm{p}<0.001)$. By contrast, inflammation in the immune-suppressed infection group in the early (the 3rd day) period was obvious, and the pathological score $(11.67 \pm 0.63)$ was increased $(\mathrm{p}<0.001)$. Additionally, inflammation in the immune-suppressed infection group in the late ( 7 th day) period was present, and the pathological score $(8.92 \pm 0.514)$ was higher than those for the control and infection groups $(\mathrm{p}<0.001)$.

Immunohistochemical analysis of TLR4. TLR4 protein expression in lung of each group at different time points was examined (Fig. 2). A mild TLR4 expression was observed in the bronchial epithelium and alveolar epithelial cell plasma of the control and infection groups, and the plasma was brown-stained and scattered. Compared with the control group, the number of macrophages in the early period of pulmonary infection was increased, and brown stained with particle aggregation. In addition, the expression of TLR4 was upregulated. The number of macrophages was rare in the late period of infection, and there was no significant difference in TLR4 expression compared with the control group, with the brown particles in the cells decreasing significantly. In the immune-suppressed infection group, bronchial epithelial and alveolar epithelial cells were yellow in the early period of pulmonary infection, and no alveolar macrophages and TLR4 expression were observed in the pulmonary tissue. In the late period, lung macrophages increased significantly, were brown 


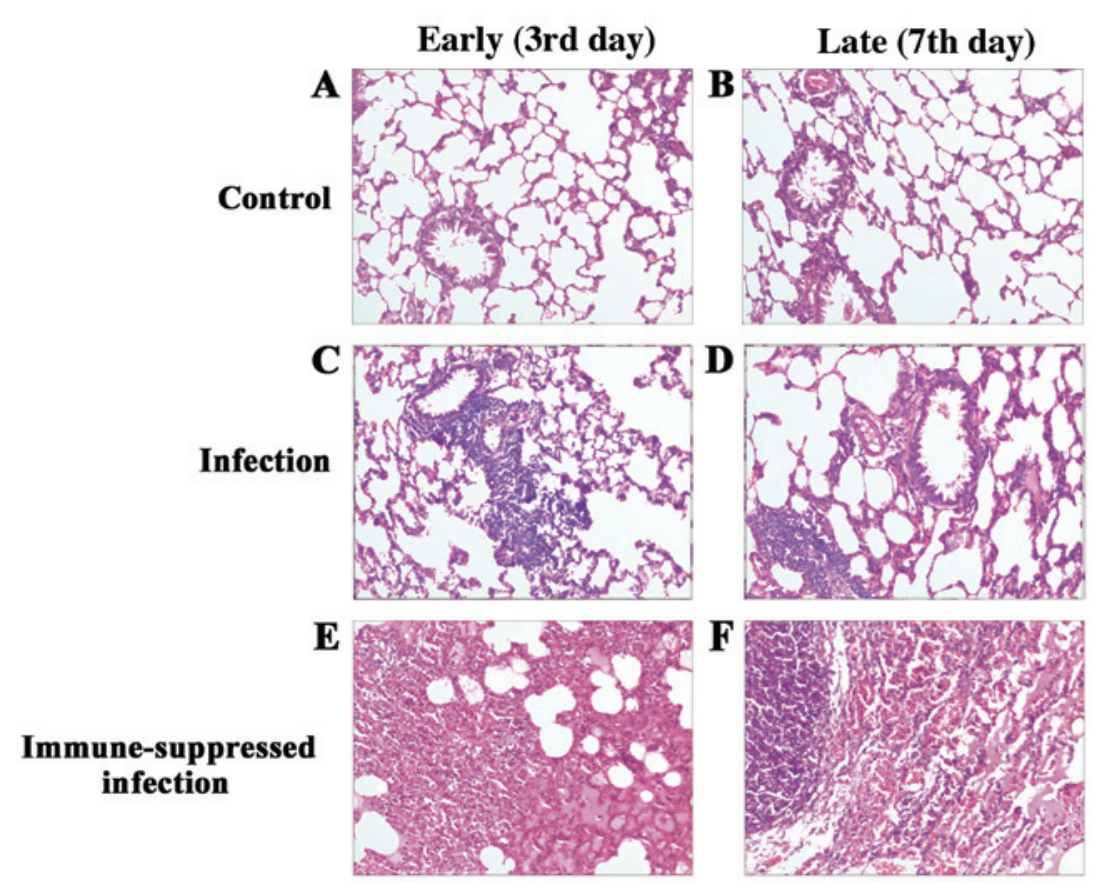

Figure 1. H\&E staining for the different groups. (A) Early control group (3rd day). (B) Late control group (7th day). (C) Early infection group (3rd day). (D) Late infection group (7th day). (E) Early immune-suppressed infection group (3rd day). (F) Late immune-suppressed infection group (7th day). H\&E, hematoxylin and eosin. Original magnification, x100.

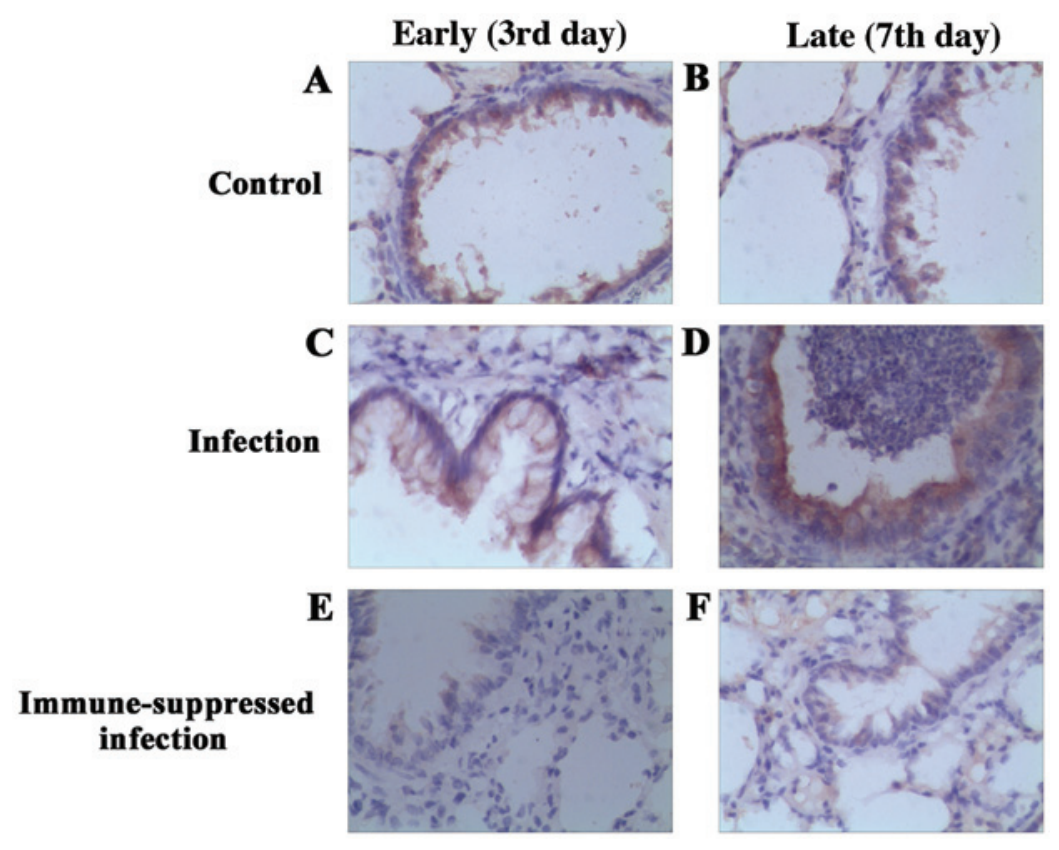

Figure 2. Immunohistochemistry for the different groups. (A) Early control group (3rd day). (B) Late control group (7th day). (C) Early infection group (3rd day). (D) Late infection group (7th day). (E) Early immune-suppressed infection group (3rd day). (F) Late immune-suppressed infection group (7th day). Original magnification, $\mathrm{x} 400$.

stained with particle aggregation, and the expression of TLR4 improved. The expression and comparison of TLR4 protein of bronchial and lung tissues in each group are shown in Fig. 3.

The comparison of the IOD values of TLR4 expression showed that in the early infection group (3rd day), the IOD value of TLR 4 expression of lung tissue $(0.78 \pm 0.08) \times 10^{4}$ markedly increased compared with the control group, which had a statistically significant difference $(p<0.05)$. In the late infection group (7th day), compared with the control group, there was no significant improvement in the IOD value of TLR4 expression of lung tissue $(0.46 \pm 0.09) \times 10^{4}$, and there was no significant difference $(p>0.05)$. In the early immune-suppressed infection group (3rd day), the IOD value of TLR4 expression of lung tissue $(0.23 \pm 0.08) \times 10^{4}$ was lower than that in the control and infection groups, which had a statistically significant difference $(\mathrm{p}<0.05)$. In the late immune-suppressed infection group (the 


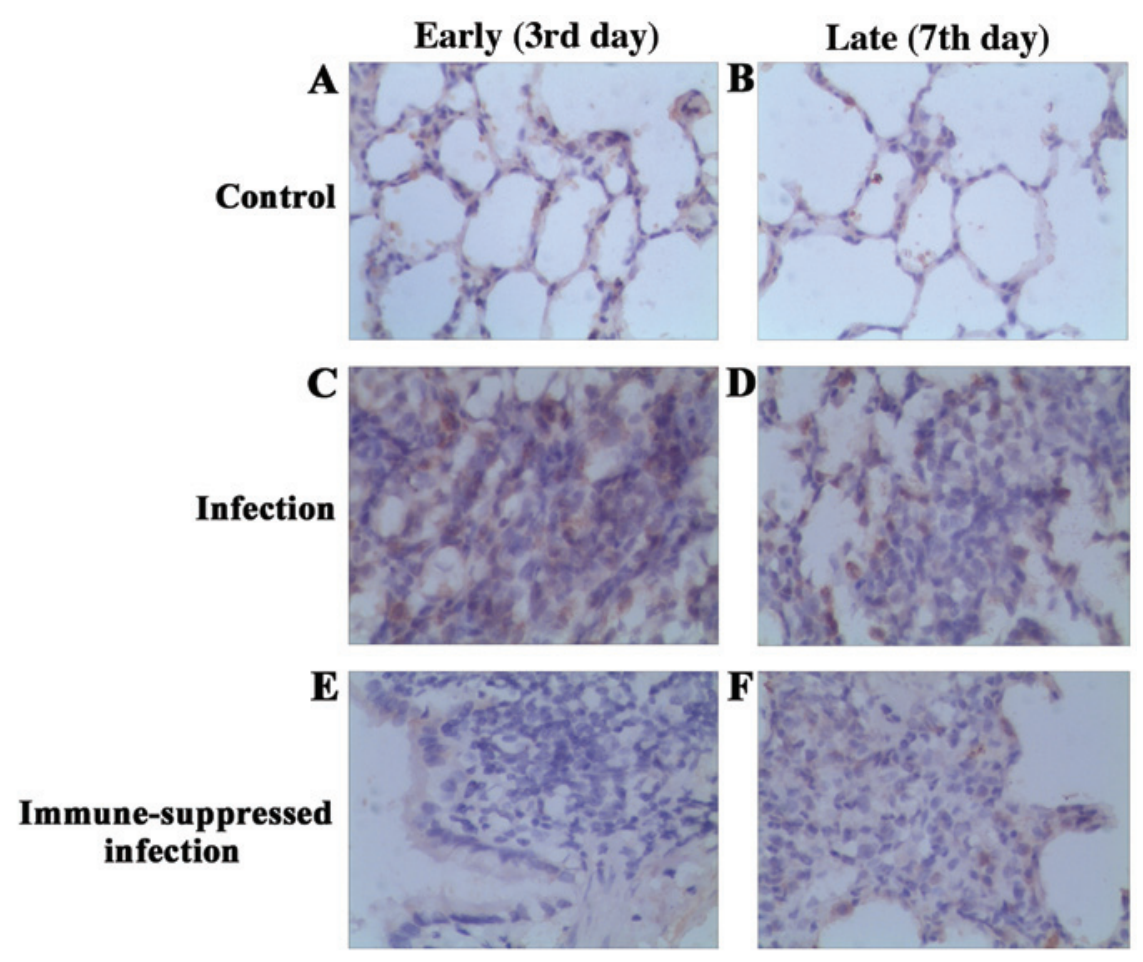

Figure 3. Immunohistochemistry of pulmonary alveoli for the different groups. (A) Early control group (3rd day). (B) Late control group (7th day). (C) Early infection group (3rd day). (D) Late infection group (7th day). (E) Early immune-suppressed infection group (3rd day). (F) Late immune-suppressed infection group (7th day). Original magnification, $\mathrm{x} 400$.

Table III. IOD value of TLR4 expression in each group $\left(\mathrm{x} 10^{4}\right)$ $($ mean $\pm \mathrm{SD})$.

\begin{tabular}{llc}
\hline Groups & $\begin{array}{c}\text { Early stage } \\
\text { (3rd day) }\end{array}$ & $\begin{array}{c}\text { Late stage } \\
\text { (7th day) }\end{array}$ \\
\hline Control & $0.46 \pm 0.08$ & $0.42 \pm 0.11$ \\
Infection & $0.78 \pm 0.08^{\mathrm{a}}$ & $0.46 \pm 0.09$ \\
Immune-suppressed & $0.23 \pm 0.08^{\mathrm{a}, \mathrm{b}}$ & $0.56 \pm 0.16$ \\
infection & & \\
\hline
\end{tabular}

${ }^{\mathrm{a} C}$ Compared with the control group, $\mathrm{p}<0.05 .{ }^{\mathrm{b}} \mathrm{Compared}$ with the infection group, $\mathrm{p}<0.05$. Lung tissue A. baumannii load. IOD, integral optical density; TLR4, Toll-like receptor 4.

7 th day), there was no significant difference between the IOD value of TLR4 expression of lung tissue $(0.56 \pm 0.16) \times 10^{4}$ and that in the control and infection groups $(\mathrm{p}>0.05)$ (Table III).

A. baumannii count. In the early infection group (3rd day), the A. baumannii count after 24 h culture was $2.7 \pm 0.50 \times 10^{8} \mathrm{CFU}$. In the late infection group ( 7 th day), the A. baumannii count was $0.05 \pm 0.02 \times 10^{8} \mathrm{CFU}$ and there was no difference compared with that in the control group (the 7 th day) (Table IV).

In the early immune-suppressed infection group (3rd day), the A. baumannii count was $24.08 \pm 8.3 \times 10^{8}$ CFU. In the late immune-suppressed infection group ( 7 th day), the A. baumannii count was $2.58 \pm 0.51 \times 10^{8} \mathrm{CFU}$, and the bacterial load capacity was significantly higher than that of the infection group $(\mathrm{p}<0.001)$ (Table IV).
Table IV. Count of the load capacity of Acinetobacter baumannii in lung tissue $\left(\times 10^{8} \mathrm{CFU}\right.$, median) (mean $\left.\pm \mathrm{SD}\right)$.

\begin{tabular}{lcc}
\hline Groups & $\begin{array}{c}\text { Early stage } \\
\text { (3rd day) }\end{array}$ & $\begin{array}{c}\text { Late stage } \\
\text { (7th day) }\end{array}$ \\
\hline Control & 0 & 0 \\
Infection & $2.7 \pm 0.50$ & $0.05 \pm 0.02$ \\
Immune-suppressed & $24.08 \pm 8.3^{\mathrm{a}}$ & $2.58 \pm 0.51^{\mathrm{b}}$ \\
infection & & \\
\hline
\end{tabular}

${ }^{\mathrm{a}}$ Compared with the control group, $\mathrm{p}=0.03$; ${ }^{\mathrm{b}} \mathrm{Compared}$ with the infection group, $\mathrm{p}<0.001$.

Levels of IL-6 and TNF- $\alpha$ of alveolar lavage fluid in each group at different time points. In the early infection group (3rd day), the content of IL-6 of the alveolar lavage fluid (733.92 \pm 12.48$)$ markedly increased compared with the control group, which had a statistically significant difference $(p=0.003)$. In the late infection group (7th day), the content of IL-6 of the alveolar lavage fluid (55.17 \pm 6.72$)$ markedly increased compared with the control group, which had a statistically significant difference $(\mathrm{p}<0.05)$ (Table V).

In the early immune-suppressed infection group (the 3rd day), the content of IL- 6 of the alveolar lavage fluid (41.92 \pm 9.67$)$ decreased significantly compared with the infection group, which had a statistically significant difference $(p=0.003)$. In the late immune-suppressed infection group ( 7 th day), the content of IL-6 of the alveolar lavage fluid (134.65 \pm 20.88 ) markedly increased compared with the infection group, which had a statistically significant difference $(p=0.03)$ (Table V). 
Table V. Content of IL-6 in each group at different time points $($ mean $\pm \mathrm{SD})$.

\begin{tabular}{lcc}
\hline Groups & $\begin{array}{c}\text { Early stage } \\
(3 \text { rd day })\end{array}$ & $\begin{array}{c}\text { Late stage } \\
(7 \text { th day })\end{array}$ \\
\hline Control & $12.19 \pm 3.61$ & $16.18 \pm 7.21$ \\
Infection & $733.92 \pm 12.48^{\mathrm{a}}$ & $55.17 \pm 6.72^{\mathrm{b}}$ \\
Immune-suppressed & $41.92 \pm 9.67^{\mathrm{c}}$ & $134.65 \pm 20.88^{\mathrm{d}}$ \\
infection & & \\
\hline
\end{tabular}

Compared with the control group, ${ }^{\mathrm{a}} \mathrm{p}=0.003,{ }^{\mathrm{b}} \mathrm{p}<0.001$. Compared with the infection group, ${ }^{\mathrm{c}, \mathrm{d}} \mathrm{p}=0.03$. IL-6, interleukin- 6 .

Table VI. Content of TNF- $\alpha$ in each group at different time points (mean $\pm \mathrm{SD})$.

\begin{tabular}{lcc}
\hline Groups & $\begin{array}{c}\text { Early stage } \\
\text { (3rd day) }\end{array}$ & $\begin{array}{c}\text { Late stage } \\
\text { (7th day) }\end{array}$ \\
\hline Control & $7.09 \pm 1.02$ & $4.33 \pm 0.72$ \\
Infection & $203.33 \pm 33.35^{\mathrm{a}}$ & $39.5 \pm 11.63^{\mathrm{b}}$ \\
Immune-suppressed & $5.0 \pm 1.63^{\mathrm{c}}$ & $143.75 \pm 38.47^{\mathrm{d}}$ \\
infection & &
\end{tabular}

Compared with the control group, ${ }^{\mathrm{a}} \mathrm{p}<0.001,{ }^{\mathrm{b}} \mathrm{p}=0.006$. Compared with the infection group, ${ }^{\mathrm{c}} \mathrm{p}<0.001,{ }^{\mathrm{d}} \mathrm{p}=0.02$. TNF- $\alpha$, tumor necrosis factor- $\alpha$.

In the early infection group (3rd day), the content of TNF- $\alpha$ of the alveolar lavage fluid $(203.33 \pm 33.35)$ markedly increased compared with the control group, which had a statistically significant difference $(p<0.001)$. In the late infection group (7th day), the content of TNF- $\alpha$ of the alveolar lavage fluid (39.5 \pm 11.63$)$ markedly increased compared with the control group, which had a statistically significant difference (Table VI).

In the early immune-suppressed infection group (3rd day), the content of TNF- $\alpha$ of the alveolar lavage fluid $(5.0 \pm 1.63)$ decreased significantly compared with the infection group, which had a statistically significant difference $(p<0.001)$. In the late immune-suppressed infection group (7th day), the content of TNF- $\alpha$ of the alveolar lavage fluid $(143.75 \pm 38.47)$ markedly increased compared with the infection group, which had a statistically significant difference (Table VI).

\section{Discussion}

In the present study, we demonstrated under the stimulation of A. baumannii that the expression of TLR4 was upregulated in the bronchial epithelial cells, neutrophils and alveolar macrophages. The secretion of IL- 6 and TNF- $\alpha$ in BALF were increased, which activated more neutrophils and macrophages in lung to phagocytic bacteria. However, TLR4 expression of the lower respiratory tract in immunosuppressed rats was downregulated. In addition, the downregulated expression of TLR4 was accompanied with reduced IL- 6 and TNF- $\alpha$ secretion and the reduced elimination of A. baumannii on the 3rd day after infection. In the subsequent recovery period, the expression of TLR4 was upregulated and the levels of IL-6 and TNF- $\alpha$ were increased.

The main modeling methods in the research of the lung infection of A. baumannii at home and abroad were: i) nose drip, or body was placed in a closed atomization generator, then an amount of aerosol particles were used to cause infection. This method cannot ensure successful inoculation. Additionally, bacteria entered in the lungs randomly and without uniformity; and ii) A. baumannii was dripped through endotracheal intubation, and when the dosage was established, uniformity of A. baumannii entering lung was also improved. However, this method requires the anesthesia of animals, and an increase in nursing work and mortality risk $(16,17)$. In the present study, A. baumannii suspension was applied through tracheal instillation and the right lower lung of rats was extracted directly for cultivating quantitatively to confirm that both the infection model and immune-suppressed rats model were successful. At the same time, the pathological results showed great inflammatory cell infiltration, pulmonary interstitial and alveolar edema, and hemorrhage on the third day after infection. Our results showed the general appearance of lung tissue, or using H\&E staining, clear lung tissue inflammation, associated with an increase in the concentration of relevant inflammatory cytokines, such as TNF- $\alpha$ and IL-6, both present in BAL. With the extension of the infection time, the degree of inflammation was reduced, resulting in the decrease of A. baumannii.

We have shown that TLR4 protein in bronchial epithelial cells of rats was highly expressed in the cell membrane and cytoplasm in the infection group, and TLR4 protein in lung tissue was only expressed in cytoplasm of alveolar macrophages and a small amount of alveolar epithelial cells. Our immunohistochemical analysis revealed that, on the 3rd day of infection, TLR4 expression of alveolar macrophages was significantly increased compared with that in the control group, with statistical significance. On the 7th day of infection, with the ease of inflammation degree, TLR4 expression of alveolar macrophages was decreased, and there were no statistical differences compared with that in the control group. The results showed a high TLR4 expression of macrophages predicted good prognosis of A. baumannii pulmonary infection. This result is consistent with those of other studies which showed that the TLR4 receptor expression of macrophage in plasma of the patients after cardiac surgery decreased, potentially increasing the susceptibility of the A. baumannii infection (10).

Although this experiment was not involved in the study of macrophage TLR4 mRNA, other studies showed that A. baumannii induced the expression of macrophage TLR4 mRNA (5). A. baumannii with LPS deficiency failed to stimulate macrophages to release TNF- $\alpha$, suggesting that TLR4 played an important role in the process of LPS-activated macrophage TLR4 expression and induced the TNF- $\alpha$ expression (9).

A number of common methods were employed in the establishment of immune-suppressed infection model: i) cyclophosphamide-treated, or diabetic rats were used; ii) cyclophosphamide in conjunction with hydrocortisone was used; iii) hydrocortisone was used alone $(16,18-23)$. The 
hydrocortisone model was used in this study, since single use of hydrocortisone decreased TLR4 expression of monocyte and the level of serum TNF- $\alpha$ and IL-1 $\beta$, significantly delaying the elimination of bacteria $(22,24,25)$.

Our results have shown that hydrocortisone-treated rats exhibit significantly increased bacterial burdens in the lungs, as well as more severe lung pathology compared with those in the control rats. Our findings have also shown that the expression of TLR4 protein was significantly decreased in the immune-suppressed rats with A. baumannii infection, together with a decrease in the expression of IL- 6 and TNF- $\alpha$. It is suggested that a decreased expression of TLR4 of alveolar macrophages in immune-suppressed rats may downregulate the bactericidal effect mediated by IL- 6 . On the other hand, when inoculated with A. baumannii, the immune-suppressed rats had a very small pulmonary inflammatory response with reduced inflammatory cells, although an obvious pulmonary edema in the lung appeared. We hypothesized that alveolar macrophage was the main effector cell on the over-activation of alveolar macrophages leading to the over-activation of $\mathrm{NF}-\kappa \mathrm{B}$, which upregulated TLR4 expression, thus a positive feedback between TLR4 and $\mathrm{NF}-\kappa \mathrm{B}$ promotes acute lung injury. This speculation remain to be investigated in the future.

In conclusion, by studying the immunosuppressive rat model, TLR4 expression of $A$. baumannii in immune-suppressed rats decreased, alveolar macrophages were reduced, the secretion of IL- 6 and TNF- $\alpha$ was reduced, and the phagocytic function of macrophage significantly was weakened, which indicated that a low expression of TLR4 and exacerbated A. baumannii infection mediated amplification, and resulted in aggravated A. baumannii infection and early death. Therefore, the enhanced expression of TLR4 protein in alveolar macrophages is a potential treatment for A. baumannii infection.

\section{References}

1. Pierri MD, Crescenzi G2, Capestro F, Recanatini C, Manso E, D'errico MM, Prospero E, Barbadoro P and Torracca L: Risk factors and impact on clinical outcome of multidrug-resistant Acinetobacter baumannii acquisition in cardiac surgery patients J Cardiothorac Vasc Anesth: Aug 24, 2015 (Epub ahead of print). doi: 10.1053/j.jvca.2015.08.024.

2. Almomani BA, McCullough A, Gharaibeh R, Samrah S and Mahasneh F: Incidence and predictors of 14-day mortality in multidrug-resistant Acinetobacter baumannii in ventilator-associated pneumonia. J Infect Dev Ctries 9: 1323-1330, 2015.

3. Özvatan T, Akalın H, Sınırtaş M, Ocakoğlu G, Yılmaz E, Heper Y, Kelebek N, İsçimen R and Kahveci F: Nosocomial Acinetobacter pneumonia: treatment and prognostic factors in 356 cases. Respirology 21: 363-369, 2016.

4. Chillappagari S, Venkatesan S, Garapati V, Mahavadi P, Munder A, Seubert A, Sarode G, Guenther A, Schmeck BT, Tümmler B, et al: Impaired TLR4 and HIF expression in cystic fibrosis bronchial epithelial cells downregulates hemeoxygenase- 1 and alters iron homeostasis in vitro. Am J Physiol Lung Cell Mol Physiol 307: L791-L799, 2014.

5. Ren W, Wang Z, Hua F and Zhu L: Plasminogen activator inhibitor-1 regulates LPS-induced TLR4/MD-2 pathway activation and inflammation in alveolar macrophages. Inflammation 38: 384-393, 2015.

6. Erridge C, Moncayo-Nieto OL, Morgan R, Young M and Poxton IR: Acinetobacter baumannii lipopolysaccharides are potent stimulators of human monocyte activation via Toll-like receptor 4 signalling. J Med Microbiol 56: 165-171, 2007.

7. Rivas-Santiago B and Juárez E: Toll-like receptor in lung response to pathogens. Rev Invest Clin 59: 481-488, 2007 (In Spanish).
8. Ubagai T, Nakano R, Nakano A, Kamoshida G and Ono Y: Gene expression analysis in human polymorphonuclear leukocytes stimulated by LPSs from nosocomial opportunistic pathogens. Innate Immun 21: 802-812, 2015

9. Moffatt JH, Harper M, Mansell A, Crane B, Fitzsimons TC, Nation RL, Li J, Adler B and Boyce JD: Lipopolysaccharide-deficient Acinetobacter baumannii shows altered signaling through host Toll-like receptors and increased susceptibility to the host antimicrobial peptide LL-37. Infect Immun 81: 684-689, 2013.

10. Kim CH, Jeong YJ, Lee J, Jeon SJ, Park SR, Kang MJ, Park JH and Park JH: Essential role of toll-like receptor 4 in Acinetobacter baumannii-induced immune responses in immune cells. Microb Pathog 54: 20-25, 2013

11. Ji J, von Scheele I, Billing B, Dahlen B, Lantz AS, Larsson K and Palmberg L: Effects of budesonide on toll-like receptor expression in alveolar macrophages from smokers with and without COPD. Int J Chron Obstruct Pulmon Dis 11: 1035-1043, 2016.

12. Joh EH, Gu W and Kim DH: Echinocystic acid ameliorates lung inflammation in mice and alveolar macrophages by inhibiting the binding of LPS to TLR4 in NF-kappaB and MAPK pathways. Biochem Pharmacol 84: 331-340, 2012.

13. Ren WY, Zhu L, Hua F, Jin JJ and Cai YY: The effect of lipopolysaccharide on gene expression of TLR4 and MD-2 in rat alveolar macrophage and its secretion of inflammation cytokines. Zhonghua Jie He He Hu Xi Za Zhi 33: 367-371, 2010 (In Chinese).

14. Kim MY, Muto J and Gallo RL: Hyaluronic acid oligosaccharides suppress TLR3-dependent cytokine expression in a TLR4-dependent manner. PLoS One 8: e72421, 2013.

15. Chen H, Cowan MJ, Hasday JD, Vogel SN and Medvedev AE: Tobacco smoking inhibits expression of proinflammatory cytokines and activation of IL-1R-associated kinase, p38, and NF-kappaB in alveolar macrophages stimulated with TLR2 and TLR4 agonists. J Immunol 179: 6097-6106, 2007.

16. Manepalli S, Gandhi JA, Ekhar VV, Asplund MB, Coelho C and Martinez LR: Characterization of a cyclophosphamide-induced murine model of immunosuppression to study Acinetobacter baumannii pathogenesis. J Med Microbiol 62: 1747-1754, 2013.

17. Thompson MG, Black CC, Pavlicek RL, Honnold CL, Wise MC, Alamneh YA, Moon JK, Kessler JL, Si Y, Williams R, et al: Validation of a novel murine wound model of Acinetobacter baumannii infection. Antimicrob Agents Chemother 58: 1332-1342, 2014

18. Sugui JA, Pardo J, Chang YC, Zarember KA, Nardone G, Galvez EM, Müllbacher A, Gallin JI, Simon MM and Kwon-Chung KJ: Gliotoxin is a virulence factor of Aspergillus fumigatus: gliP deletion attenuates virulence in mice immunosuppressed with hydrocortisone. Eukaryot Cell 6: 1562-1569, 2007.

19. Adamson TW, Diaz-Arevalo D, Gonzalez TM, Liu X and Kalkum M: Hypothermic endpoint for an intranasal invasive pulmonary aspergillosis mouse model. Comp Med 63: 477-481, 2013.

20. Diaz-Arevalo D, Bagramyan K, Hong TB, Ito JI and Kalkum M: $\mathrm{CD}^{+} \mathrm{T}$ cells mediate the protective effect of the recombinant Asp f3-based anti-aspergillosis vaccine. Infect Immun 79: 2257-2266, 2011

21. Lewis RE, Liao G, Hou J, Chamilos G, Prince RA and Kontoyiannis DP: Comparative analysis of amphotericin B lipid complex and liposomal amphotericin B kinetics of lung accumulation and fungal clearance in a murine model of acute invasive pulmonary aspergillosis. Antimicrob Agents Chemother 51: 1253-1258, 2007.

22. Heller AR, Heller SC, Borkenstein A, Stehr SN and Koch T: Modulation of host defense by hydrocortisone in stress doses during endotoxemia. Intensive Care Med 29: 1456-1463, 2003.

23. Luo G, Spellberg B, Gebremariam T, Bolaris M, Lee H, Fu Y, French SW and Ibrahim AS: Diabetic murine models for Acinetobacter baumannii infection. J Antimicrob Chemother 67: 1439-1445, 2012.

24. Bagheri B, Sohrabi B, Movassaghpour AA, Mashayekhi S, Garjani A, Shokri M, Pezeshkian M and Garjani A: Hydrocortisone reduces Toll-like receptor 4 expression on peripheral $\mathrm{CD}^{+} 4^{+}$monocytes in patients undergoing percutaneous coronary intervention. Iran Biomed J 18: 76-81, 2014.

25. Agustí C, Rañó A, Filella X, González J, Moreno A, Xaubet A and Torres A: Pulmonary infiltrates in patients receiving long-term glucocorticoid treatment: etiology, prognostic factors, and associated inflammatory response. Chest 123: 488-498, 2003. 